\title{
Localization of $\mathrm{CO}_{2}$ Sensor Related to the Inhibition of the Bullfrog Respiration
}

\author{
Yoshikazu SAKakibara \\ Department of Physiology, School of Medicine, Chiba University, \\ Inohana, Chiba, 280 Japan
}

\begin{abstract}
CO}_{2}$ sensitivity in the airways and the general skin surface of the bullfrog under urethane anesthesia or without anesthesia was investigated. Pressure in the buccal cavity as well as blood pressure in the sciatic artery were measured with a differential or a straingauge transducer. Air containing $2-14 \% \mathrm{CO}_{2}$ was introduced into the regions as given below. (1) The nose and the body surface, both regions were separated from each other and independently exposed to $\mathrm{CO}_{2}$. (2) The larynx-lungs, the buccal cavity-lungs, the naso-buccal cavity separated from the airways at the glottis, and the internal or external nares, respectively. By analyzing the $\mathrm{CO}_{2}$ sensitivity of the respective regions mentioned above, both the nasal mucosa and the skin surface were found to be responsible for the respiratory inhibition by $\mathrm{CO}_{2}$. Sectioning both the olfactory and the trigeminal nerves abolished the $\mathrm{CO}_{2}$-induced inhibition mediated by the nasal mucosa and electrical stimulation of the proximal cut end of these nerves inhibited respiration. These findings suggested the existence of afferent reflex pathways from the nasal mucosa by these cranial nerves. Significance of this $\mathrm{CO}_{2}$-induced reflex was discussed.
\end{abstract}

$\mathrm{CO}_{2}$ administered to bullfrogs elicits respiratory inhibition although increased blood $P_{\mathrm{CO}_{2}}$ with decreased $\mathrm{pH}$ ultimately augments ventilation (SAKAKIBARA and AкIYAma, 1977). Sмутн (1939) presumed that this respiratory inhibition by $\mathrm{CO}_{2}$ is induced by a reflex mechanism and the receptors are located in the glottis and the larynx. However, there has so far been no investigation confirming his assumption. In this study, it was intended that the following problems be solved. (1) Are both the skin surface and the airways involved in the $\mathrm{CO}_{2}$ inhibition response? (2) Are the $\mathrm{CO}_{2}$ sensors actually located in the larynx and the glottis as assumed by Smyth? (3) What sensory nerves in the airways are concerned with this inhibitory reflex?

\section{MATERIALS AND METHODS}

Bullfrogs (Rana catesbeiana) captured in Saitama or Chiba prefecture during

Received for publication December 15, 1977

梉原吉一 
winter to summer were supplied by Nippon Bio-Materials Supplying Center Co., Ltd. They were kept in a humidified cage at ambient temperature and with light regimen for several days or weeks till experimental usage.

Thirty-three bullfrogs were used for the experiments. They were strained on an animal board and prepared under ether anesthesia. $\mathrm{CO}_{2}$ tests were performed 2 to $3 \mathrm{hr}$ after preparation. In some cases experiments were carried out under urethane anesthesia induced by immersing the whole frog in $1-2 \%$ urethane solution. The design of experiments was shown in Table 1 and Fig. 1 . The ex-

Table 1. Experimental designs for the series of experiments.

\begin{tabular}{|c|c|c|c|c|c|c|c|}
\hline Exp. & $\begin{array}{l}\text { Areas } \\
\text { explored }\end{array}$ & $\begin{array}{l}\text { Types of } \\
\text { stimuli }\end{array}$ & $\begin{array}{l}\text { No. of } \\
\text { buccal } \\
\text { cannulae }\end{array}$ & $\begin{array}{l}\text { No. of } \\
\text { lung } \\
\text { cannulae }\end{array}$ & $\begin{array}{l}\text { Nose } \\
\text { mask }\end{array}$ & $\begin{array}{l}\text { In or out } \\
\text { of chamber } \\
\text { (exp. } \\
\text { conducted) }\end{array}$ & $\begin{array}{c}\text { Blood } \\
\text { pressure } \\
\text { measure- } \\
\text { ment }\end{array}$ \\
\hline I & Skin and airway & $\mathrm{CO}_{2}$ & 1 & 0 & + & In & - \\
\hline II-1) & Larynx-lungs & $\mathrm{CO}_{2}$ & 1 & 2 & - & In & - \\
\hline 2) & Buccal-lungs & $\mathrm{CO}_{2}$ & 2 & 0 & - & In & - \\
\hline 3) & Nose & $\mathrm{CO}_{2}$ & 2 & 0 & - & In & - \\
\hline III & $\begin{array}{l}\text { Ist and Vth } \\
\text { cranial nerves }\end{array}$ & $\mathrm{CO}_{2}$ & 1 & 0 & + & In & - \\
\hline IV & Same as above & $\begin{array}{l}\text { electric } \\
\text { stimulation }\end{array}$ & 1 & 0 & - & Out & + \\
\hline
\end{tabular}

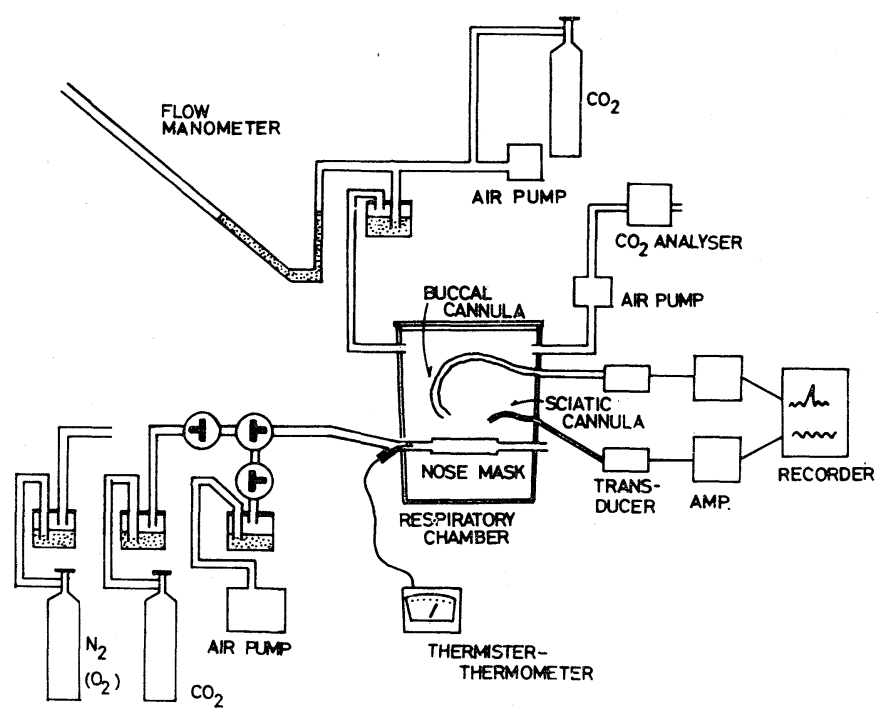

Fig. 1. Experimental set up. The frog was connected to a nose mask and placed in the respiratory chamber. To the nose mask or the chamber, air or various kinds of gas mixtures were separately supplied by an air pump or gas cylinders through humidifying bottles. $\mathrm{CO}_{2}$ concentration in the chamber was adjusted by using a water manometer as well as an infrared $\mathrm{CO}_{2}$ analyser. The temperature in the nose mask, pressure in the buccal cavity and in the sciatic artery were measured. 
perimental procedures were as follows.

1) Respiratory movement: A cannula (2 $\mathrm{mm}$ in diameter) was inserted into the buccal cavity through the cranium behind the eye which could be conducted with little bleeding. Its outer end was connected to a differential pressure transducer (DLPU-0.05 Nihon Kohden) to record the respiratory pressure change in the buccal cavity.

2) Arterial blood pressure and heart rate: A polyethylene cannula $(0.6 \mathrm{~mm}$ in diameter) was introduced into the sciatic artery and connected with a straingauge transducer (LPU-0.1-350-0II, Nihon Kohden). Heart rate was counted from the blood pressure recordings.

3) Nose mask: A rubber tube (5 $\mathrm{mm}$ in diameter, $50 \mathrm{~mm}$ in length) was adequately clipped and a small opening was made with scissors at the middle in the tube so that it could be fitted to the apex of the head around the nose; it was called a "nose mask." This was sewed up with the skin around the nose by ligating eight points using fine threads. In some cases $\alpha$-cyano acrylate monomer (aron alpha) and dental cement were used to make a mask fit tightly to the skin. These adhesive agents, however, did not always secure a success, since secretions from the skin sometimes prevented tight adhesion. Various kinds of test gases and room air were supplied with a flow rate of $90-100 \mathrm{ml} / \mathrm{min}$ through the nose mask to explore the existence of the $\mathrm{CO}_{2}$ sensor in the airways. Latency of the inhibitory response to $\mathrm{CO}_{2}$ stimulation was also observed.

4) Respiratory chamber: In Experiment I, II, and III (Table 1) frogs were placed in a respiratory chamber $(150 \times 280 \times 200 \mathrm{~mm})$ made of transparent synthetic resin. The cannulae were either connected to the transducer for pressure measurement or used to supply gas mixtures. Through a bifurcated or a single tubing inserted into the chamber wall, various gas mixtures humidified through a water bottle were supplied into the cannulae or into the nose mask. A three-way stopcock located outside the chamber in the gas mixture line was used to switch inflowing gas from cylinders over an air pump (Fig. 1). With another branch of the bifurcated cannula the pressure or the temperatures of the inflowing gases were monitored by a differential pressure transducer or thermister thermometer (MAGIII, Nihon Kohden). From another inlet of the chamber air was constantly supplied at a rate of 1-1.5 liters/min through a humidifying bottle by an air pump. The pressure of the inflowing gas was monitored by a water manometer. The level of the pressure was used as a rough indicator for the rate of airflow. Similar amounts of air were withdrawn from the chamber with another air pump to maintain the chamber pressure constant, at the same level as the atmospheric pressure.

In order to study the $\mathrm{CO}_{2}$ sensitivity of the general skin surface, $\mathrm{CO}_{2}$ was continuously added to the air in the chamber with constant velocity, being monitored by the water manometer, up to $4-5 \%$ which was measured by an infrared $\mathrm{CO}_{2}$ analyser (LIA-2B, Horiba Co., Ltd.).

5) Test gases: Preliminary study showed that $\mathrm{CO}_{2}$ less than $3 \%$ had no 
distinct effect, thus more concentrated $\mathrm{CO}_{2}$ mainly was used in the experiments. Four to $5 \% \mathrm{CO}_{2}$ in air was applied to the general skin surface as described earlier. On the other hand $5.7 \% \mathrm{CO}_{2}$ with $23 \% \mathrm{O}_{2}$ in $\mathrm{N}_{2}$ was usually supplied into the airways or the nose mask. Fourteen percent $\mathrm{CO}_{2}$ in $\mathrm{O}_{2}, 15 \% \mathrm{CO}_{2}$ in $\mathrm{O}_{2}, 2.1 \%$ $\mathrm{CO}_{2}$ with $23.5 \% \mathrm{O}_{2}$ in $\mathrm{N}_{2}$, or pure $\mathrm{CO}_{2}$ were also used. Pure $\mathrm{O}_{2}$ and $\mathrm{N}_{2}$ were also used for the control.

\section{Protocols of experiments}

I. Identification of the sensor in the airways and the skin. The frog wearing the nose mask was placed in the respiratory chamber. Air was separately and continuously supplied to the chamber as well as the nose mask. Test gas $\left(\mathrm{CO}_{2}\right.$ $5.7 \%$ and $\mathrm{O}_{2} 23 \%$ in $\mathrm{N}_{2}$ ) was supplied into the nose mask to examine $\mathrm{CO}_{2}$ sensitivity of the frog airways. Sometimes air, which was flowing into the nose mask during pre- $\mathrm{CO}_{2}$ loading, was stopped by turning off the three-way stopcock in order to examine whether a mild asphyxic condition in the nose mask elicited respiratory inhibition. Examination was followed to detect whether $\mathrm{CO}_{2}$ sensitivity of the frog skin existed with constant air flow in the nose mask.

II. Localization of $\mathrm{CO}_{2}$ sensor in the airways. 1) Perception of the larynxlungs preparation: The airway was separated into two compartments, the larynxlungs and the rest by sewing the glottis at its rostral end. Bilateral lung cannulae ( $2 \mathrm{~mm}$ in diameter) were inserted according to JONES (1970) under ether anesthesia. The frog was then placed into the respiratory chamber. Air was supplied to the lungs as well as the chamber. The lungs could not ventilate through their own buccal pump, but by artificial aeration through the cannulae the animal still showed buccal ventilation movements. Its pressure change was still a good indicator for respiratory activities.

Through lung cannulae $5.7 \% \mathrm{CO}_{2}$ was given to the lungs in order to detect $\mathrm{CO}_{2}$ sensitivity of the larynx-lungs at the same rate as the air flow, and thereafter, $\mathrm{CO}_{2}$ sensitivity of the whole body except the larynx-lungs compartments was reexamined by the same method as in protocol I.

2) Perception' of the buccal cavity-lungs preparation: The internal nares were closed by two small vinyl sticks with aron alpha or two pieces of paper with starch or vaseline. Thus, the buccal cavity-lungs area was separated from the rest of the airways. Two cannulae were then inserted into the buccal cavity (Table 1), and $5.7 \%$ or $14 \% \mathrm{CO}_{2}$ was separately and alternatively given for $30 \mathrm{sec}$ to $4 \mathrm{~min}$. After this examination, $\mathrm{CO}_{2}$ sensitivity of the whole body was also tested as described above.

3) Perception of the nasal cavity: After the above study, the stoppers of the internal nares were removed and the external nares were closed by various means: vinyl sticks with aron alpha, sewing skin around the external nares, or paper with starch. Through the two cannulae inserted into the buccal cavity, 2.1, 5.7 and $14 \% \mathrm{CO}_{2}$ were administered into the nasal cavities for $30 \mathrm{sec}$ to $4 \mathrm{~min}$. 
After this, examination of the $\mathrm{CO}_{2}$ sensitivity for the whole body was repeated.

III. The effect of denervation of the Ist and Vth cranial nerves. The frog was first sham-operated instead of by denervation of the Ist and the Vth cranial nerves, where the nasal bone, cartilage or other connective tissues were resected. $\mathrm{CO}_{2}$ sensitivity was then examined by administering the test gases through the nose mask. After denervation of either the Ist cranial nerves or the rami frontalis of the trigeminal nerves had been conducted, $\mathrm{CO}_{2}$ sensitivity was examined to see whether or not it remained. Thereafter, the remaining Vth or Ist cranial nerves in each frog were denervated and the same examination was repeated. In another case both nerves were denervated at the same time and then $\mathrm{CO}_{2}$ sensitivity was examined.

Uusually the $\mathrm{CO}_{2}$ concentration used was $5.7 \%$. However, after denervation of both the cranial nerves, $14 \% \mathrm{CO}_{2}$ particularly was used to detect if any residual $\mathrm{CO}_{2}$ sensitivity remained. The test for $\mathrm{CO}_{2}$ sensitivity in these animals was repeated for several days after the denervation.

In some experiments, after $\mathrm{CO}_{2}$ sensitivity in the airways had disappeared completely, the frog was tested to determine if the respiration could be inhibited in response to whole body $\mathrm{CO}_{2}$ administration in the respiratory chamber.

$I V$. The effect of stimulation of the Ist and Vth cranial nerves on respiration and circulation. Under urethane anesthesia, the Ist and Vth cranial nerves were exposed and the surrounding connective tissues were carefully removed. Each nerve was cut at the periphery, and its proximal stump was stimulated electrically ( $1 \mathrm{msec}$ of duration, $2-7 \mathrm{~V}$ in intensity, $1-200 \mathrm{~Hz}$ in frequency). Stimulation was repeated three times with a proper intermission during which respiration returned to normal.

\section{RESULTS}

\section{Effect of $\mathrm{CO}_{2}$ in the nose mask or in the respiratory chamber}

The humidified $5.7 \% \mathrm{CO}_{2}$ supplied through the nose mask inhibited respiration in all 3 animals. Pulmonary ventilations were almost replaced by buccal ventilations or both types of ventilations were so severely depressed that apnea was induced. An example is shown in the second row in Fig. 2. When the air flowing in the nose mask was turned off, respiration was slightly inhibited as well. This was seen in every trial conducted more than 10 times (shown also in the 2nd row in Fig. 2).

When $5.7 \% \mathrm{CO}_{2}$ was applied the latency was between 2 and $13 \mathrm{sec}$ and mostly about 4 to $8 \mathrm{sec}$ (15 trials in 3 frogs). The latency tended to be shortened with rising $\mathrm{CO}_{2}$ concentration (Fig. 3). When $\mathrm{CO}_{2}$ loading was terminated and converted to room air breathing normal respiration was resumed after a short delay. When completely suppressed, respiration needed a longer duration for its restoration than the partial inhibition. Next, while room air was given continuously through the nose mask, $\mathrm{CO}_{2}$ was added into the respiratory chamber up to 4 to $5 \%$ 


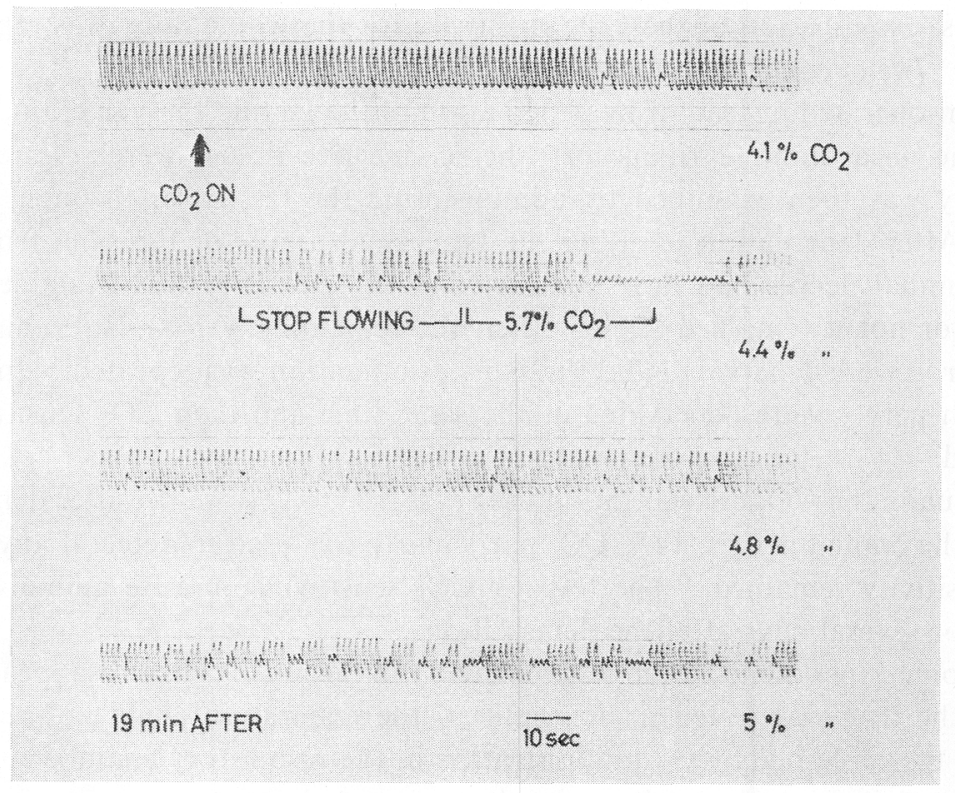

Fig. 2. Effects of $\mathrm{CO}_{2}$ in the respiratory chamber and the nose mask on respiration. Increasing the $\mathrm{CO}_{2}$ concentration to $5 \%$ in the chamber, stopping flow or inducing $5.7 \%$ $\mathrm{CO}_{2}$ in the nose mask resulted in respiratory inhibition.

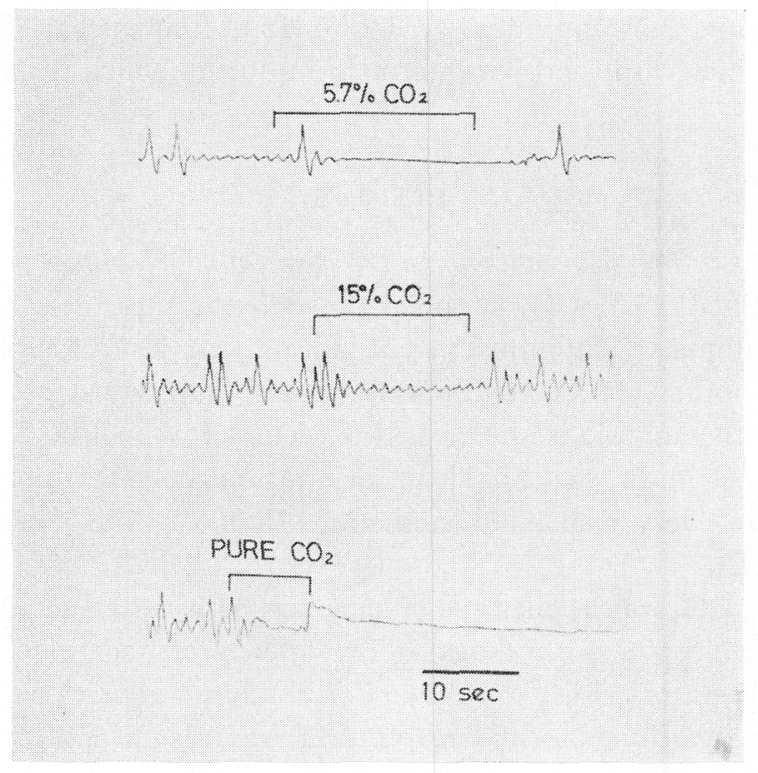

Fig. 3. Effects of varying the concentration of $\mathrm{CO}_{2}$ given through the nose mask on the respiratory inhibition. With increasing $\mathrm{CO}_{2}$ concentration, the latency of induced inhibition was shortened. 
in $\mathrm{CO}_{2}$ concentration. Figure 2 indicates that $\mathrm{CO}_{2}$ thus induced in the chamber inhibited respiration. Pulmonary ventilations were partially replaced by buccal ventilations. The $\mathrm{CO}_{2}$ inhibition induced solely via the skin, however, was variable in its extent or in latency.

II. The effects of $\mathrm{CO}_{2}$ administered into different compartments of the airways on respiration

1) The effect of $5.7 \% \mathrm{CO}_{2}$ given into the lung compartment. The frogs with larynx-lung preparation were tested. Five point seven percent $\mathrm{CO}_{2}$ administered into the lungs compartment through the bilateral cannulae inserted did not inhibit respiration but augmented it. When $5.7 \% \mathrm{CO}_{2}$ was replaced by humidified pure $\mathrm{O}_{2}$, the respiratory frequency decreased. When $\mathrm{CO}_{2}$ concentration in the chamber was raised up to about $4 \%$, respiration was prominently inhibited.

2) The effect of flowing $\mathrm{CO}_{2}$ into the buccal and lung compartment. Six frogs with the buccal cavity-lungs preparation were examined. When $5.7 \% \mathrm{CO}_{2}$ or $14 \%$ $\mathrm{CO}_{2}$ was given intermittently into the buccal cavity, respiration was unchanged in most cases. Sometimes, however, respiration increased in amplitude without any change in frequency (Fig. 4).

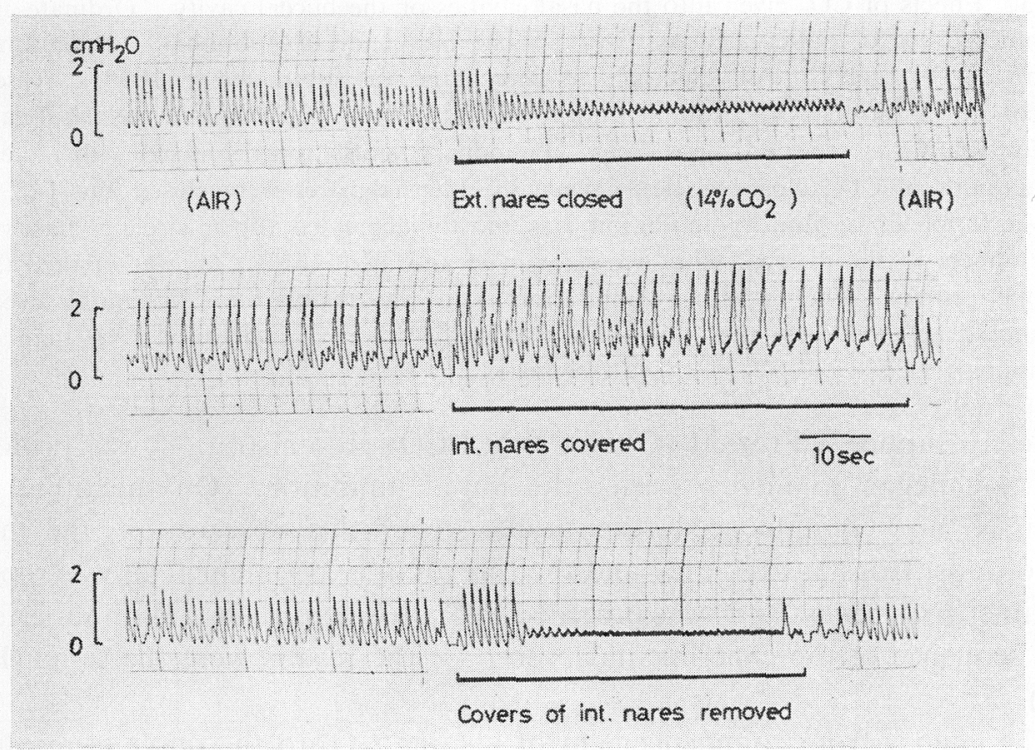

Fig. 4. Separation of the airway and effects of $\mathrm{CO}_{2}$ given to the different cavities. On the middle row, $14 \% \mathrm{CO}_{2}$ introduced into the buccal and lung compartment through the double buccal cannulae did not inhibit respiration. In the upper and lowest rows, $14 \% \mathrm{CO}_{2}$ given into the buccal and nasal cavities markedly inhibited ventilation. The lowest test was conducted after the test of the second row.

3) The effect of flowing $\mathrm{CO}_{2}$ into the buccal and the nasal cavities. Four 
frogs with closed external nares were kept breathing through the double buccal cannulae. When $5.7 \% \mathrm{CO}_{2}$ was introduced into the buccal cavity through the cannulae, more than $80 \%$ of pulmonary ventilations disappeared after a short delay. This inhibitory influence was augmented by rising $\mathrm{CO}_{2}$ concentration (Fig. 5). It was often observed that all pulmonary and buccal ventilations were

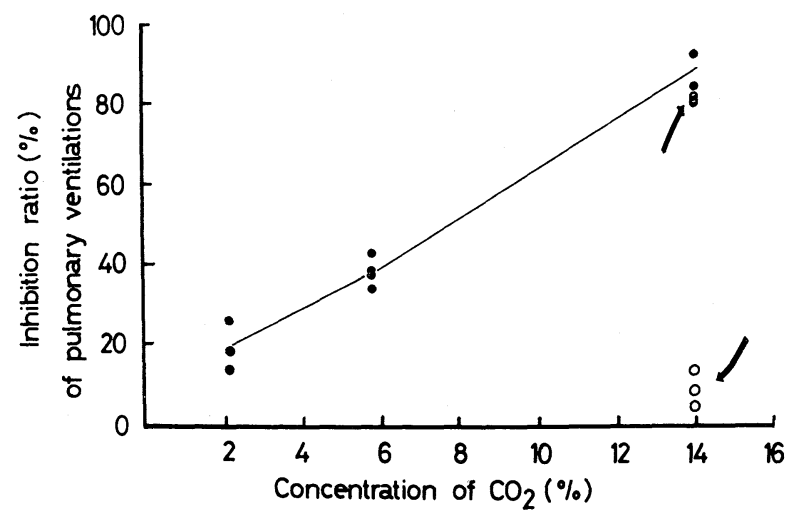

Fig. 5. Effects of $\mathrm{CO}_{2}$ given into the nasal cavities or the buccal cavity. Ordinates: inhibition ratio of pulmonary ventilation. The frequency of pulmonary ventilation was divided by each control value, and its percentage was subtracted by $100 \%$. Abscissa: concentration of $\mathrm{CO}_{2}$. Administration of $2.1,5.7$, or $14 \% \mathrm{CO}_{2}$ into the nasal cavities for $1 \mathrm{~min}$ was repeated three times. Pulmonary ventilation decreased with increasing amounts of $\mathrm{CO}_{2}$ (closed circle). When the internal nares were closed and $14 \% \mathrm{CO}_{2}$ was applied, respiratory inhibition was mostly depressed (open circle). Lastly, the stoppers of the internal nares were removed and again $14 \% \mathrm{CO}_{2}$ was applied (semiopen circle). The respiratory inhibition ratio was restored to the initial level. It should be mentioned that this animal showed less responsiveness to $\mathrm{CO}_{2}$ than other animals used in these experiments (see text).

completely suppressed for 30-60 sec. When $\mathrm{CO}_{2}$ administration was prolonged, respiration began to increase after the initial inhibition. On the other hand, neither $\mathrm{N}_{2}$ nor $\mathrm{O}_{2}$ influenced respiration. After this observation, the internal nares of most frogs again closed and the foregoing Experiment II-2) was repeated. Sometimes Experiment II-2) was preceded by Experiment II-3). Without reference to the sequence of the experimental procedure the results were the same (Figs. 4 and 5).

The latency from commencement of loading $\mathrm{CO}_{2}$ to the onset of respiratory inhibition was generally similar to the case of loading $\mathrm{CO}_{2}$ externally, i.e., from the nose mask. Sometimes pulmonary ventilations were altered to buccal ones on turning the air to $5.7 \% \mathrm{CO}_{2}$, then suppression of ventilation followed. In such cases the delay time was not clearly investigated.

In these experiments the pressure of flowing gases at the inlet of the buccal cannula was kept at the same level throughout the experiment. The temperature 
change measured in the nose mask was within $0.2^{\circ} \mathrm{C}$ throughout a given experimental series. Usually the temperature of each test gas was equal to that of the preceding room air flow in the nose mask. Such a small temperature variation was considered to have little influence on ventilation.

Although, as just mentioned, ventilatory responses were varied by introducing $\mathrm{CO}_{2}$ in different airway cavities, all the frogs observed in this section II considerably decreased their ventilations in response to $\mathrm{CO}_{2}$ introduction in the respiratory chamber. Therefore, perception of $\mathrm{CO}_{2}$ in the skin surface was considered to have been preserved.

III. The effect of denervation of the Ist and nasal branch of the Vth cranial nerves As demonstrated in the foregoing results, perception of $\mathrm{CO}_{2}$ in the airway compartment was estimated to localize in the nasal epithelium, the role of the cranial nerves innervated there were investigated.

Seven frogs were sham-operated and the nose mask mounted. Respiration
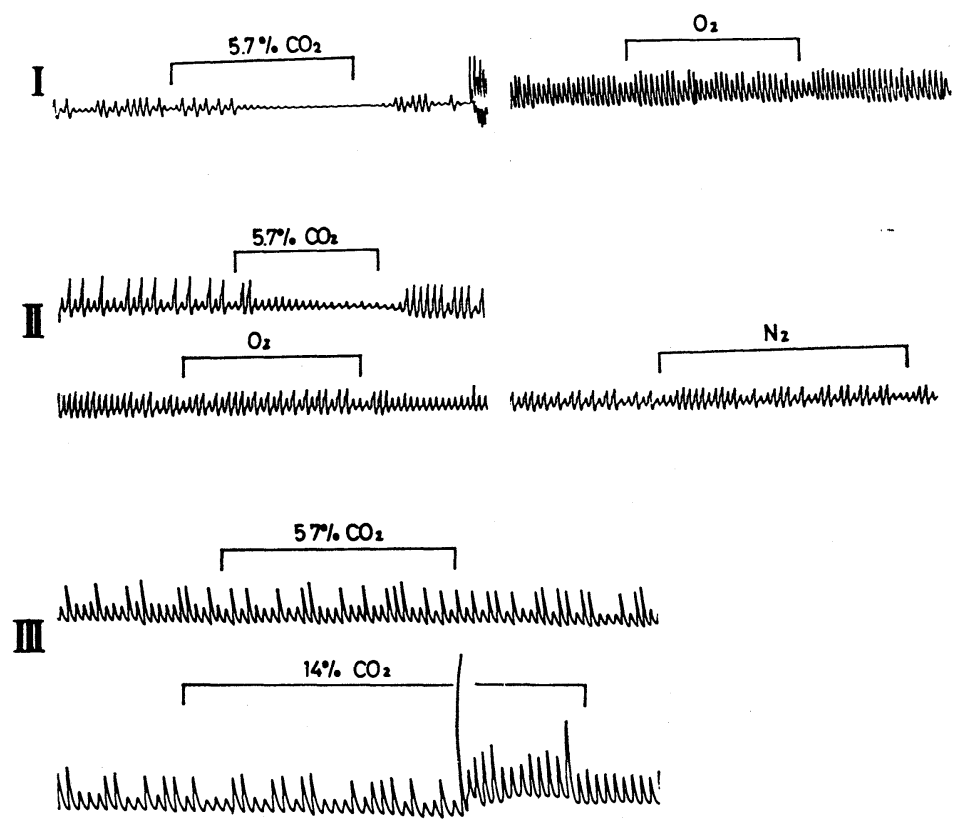

Fig. 6. $\mathrm{CO}_{2}$ sensitivity after surgical procedures for the Ist and the Vth cranial nerves. The inhibitory effect of $5.7 \% \mathrm{CO}_{2}$ supplied through the nose mask was apparent in the sham-operated animal (upper row I), and after bilateral sectioning the ramus frontalis of the trigeminal nerves (middle row II). It was abolished after bilateral sectioning of the Ist and the Vth cranial nerves (the lowest row III). $\mathrm{O}_{2}$ and $\mathrm{N}_{2}$ had no effect on this response.

Vol. 28, No. 6, 1978 
in the 5 frogs was inhibited in response to inhalation of humidified $5.7 \% \mathrm{CO}_{2}$. The latency from the commencement of $\mathrm{CO}_{2}$ inflowing, to the respiratory inhibition was $7.3 \pm 2.1 \mathrm{sec}$ (mean $\pm \mathrm{SE}, 9$ cases in 4 animals). The other 2 frogs were not affected by $5.7 \% \mathrm{CO}_{2}$. Although the reason why they did not respond to $\mathrm{CO}_{2}$ was not certain, it may have been due to the fact that drastic operational procedures exceedingly irritated the sensory elements from the surface of the nasal epithelium. It is known that mechanical stimulation of the nasal mucosa leads to excitation of medullary expiratory neurons in cats (PRICE and BATSEL, 1970), although it is not known whether such a mechanical stimulation increases respiration and/or inhibits the nasal $\mathrm{CO}_{2}$ responsiveness in frogs. Two of 5, in whom an inhibitory response by $5.7 \% \mathrm{CO}_{2}$ was demonstrated, were not available for the full course of the nerve dissection experiment, because their response was either weak or fluctuated on repeating the $\mathrm{CO}_{2}$ test for 7 days. In the other 3 frogs the olfactory nerves could be denervated as well as the rami frontalis of the Vth cranial nerves. They were repeatedly examined for the effects of $5.7 \% \mathrm{CO}_{2}$ or $14 \% \mathrm{CO}_{2}$ from immediately till 4 days after the denervation. Figure 6 indicates the results of this examination. Their respiration was no longer inhibited by $5.7 \% \mathrm{CO}_{2}$ or even by $14 \% \mathrm{CO}_{2}$. These denervated frogs still maintained a $\mathrm{CO}_{2}$ inhibitory response mediated by the skin surface. Figure 7 shows such an example where ventilation decreased as $\mathrm{CO}_{2}$ increased in the respiratory chamber.

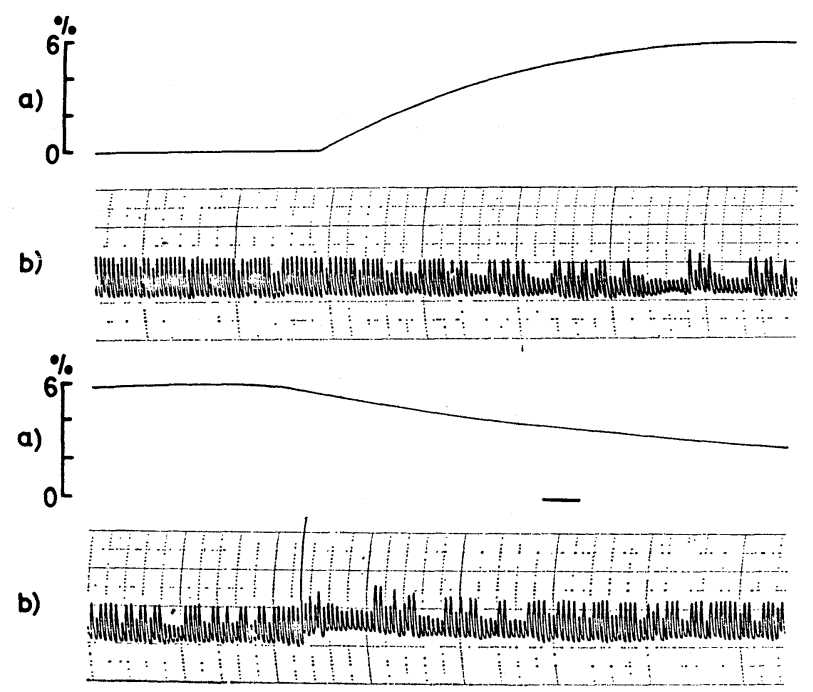

Fig. 7. $\mathrm{CO}_{2}$ sensitivity of the skin surface in the frog which lost $\mathrm{CO}_{2}$ sensitivity in the airways. The frog, which was denervated and lost $\mathrm{CO}_{2}$ sensitivity in the airways as demonstrated in Fig. 6, still decreased ventilation when $\mathrm{CO}_{2}$ was given over the skin surface. The upper and lower figures are successive recordings in one experimental run. (a) $\mathrm{CO}_{2}$ concentration in the respiratory chamber. (b) Respiratory movements. 


\section{The effects of electrical stimulation}

1) The effects of electrical stimulation of the olfactory nerves on the cardiopulmonary function of frogs. Ten of 16 frogs apparently gave decreased respiratory movements after electrical stimulation of the proximal end of the innermost medial branch of the olfactory nerves. The intensities of stimulation used were 2 to $7 \mathrm{~V}$ with $1 \mathrm{msec}$ duration. Respiration always decreased to a degree during electrical stimulation of the frequencies used in this experiment. Figure 8 demonstrates the results of one frog, No. 16. This animal gave decreased respiratory frequency and magnitude. The longest duration between one pulmonary ventilation and the next during stimulation was compared with the mean duration in the control. The former was divided by the latter. Figure 9 indicates that at $20 \mathrm{~Hz}$ electric stimulation this ratio was as high as 19 times the control respiratory

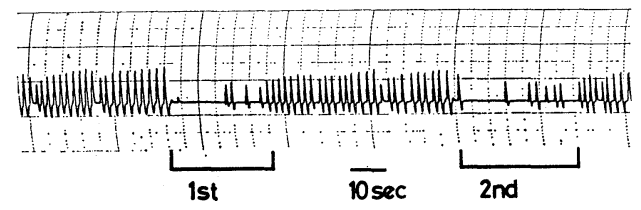

Fig. 8. Inhibitory effect of electrical stimulation of the olfactory nerves on respiration and blood pressure of frog No. 16.

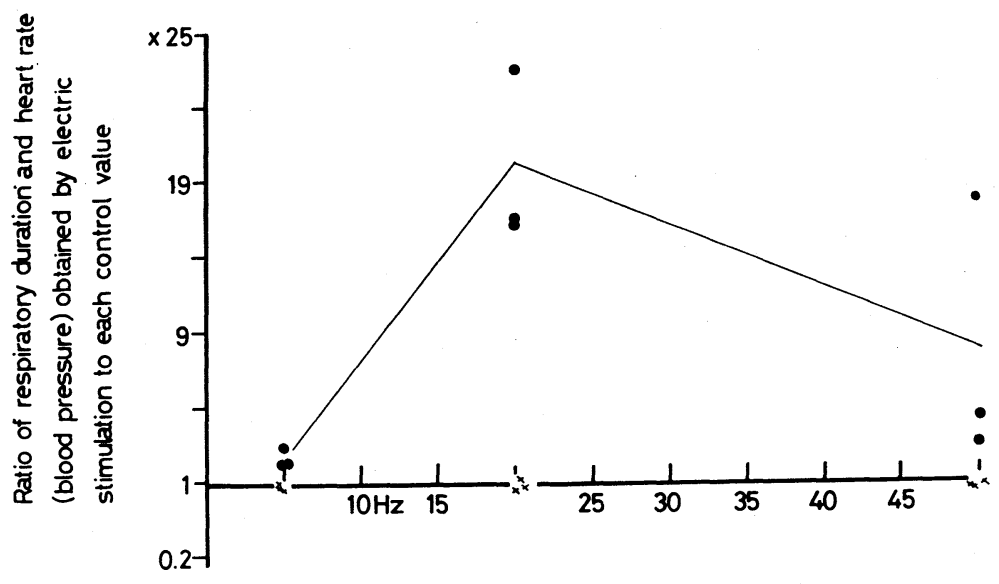

Stimulation frequency

Fig. 9. Extent of inhibitory effect of electrical stimulation of the olfactory nerves on respiration and circulation. Abscissa: frequency of electric stimulation in $\mathrm{Hz}$. Ordinate: ratio of the observed values in the respiratory period and heart rate (blood pressure) obtained by electric stimulation to their respective control values. Marked inhibition by $20 \mathrm{~Hz}$ was noticed in ventilation. On the other hand, heart rate and blood pressure were hardly influenced. The ratio of the blood pressure was similar to that of the heart rate. Closed circle, respiratory period; cross, heart rate (blood pressure). 
period (closed circle). Generally, stimulation in the range of 20 to $50 \mathrm{~Hz}$ maximally inhibited the respiration. Outside this range, both at higher and lower stimulation frequencies, respiration was less affected except one frog, No. 14. This animal showed higher respiratory frequencies during stimulation with $2 \mathrm{~Hz}$ than that of the control, while the reverse was seen with a stimulation frequency higher than $10 \mathrm{~Hz}$. Thus diphasic respiratory responses to electric stimulation were observed. The heart rate and blood pressure were also slightly depressed during electrical stimulation. The highest responses during stimulation were compared with the mean value of each control (Fig. 9). The degree of inhibition was much weaker than that seen in respiration and sometimes no suppression was observed.

2) The effects of electrical stimulation of the nasal branch of the trigeminal nerves. Three frogs were electrically stimulated at the proximal end of the ramus frontalis of the Vth cranial nerves for several seconds or minutes. These experiments were performed after electrical stimulation of the Ist cranial nerves. The intensities of electrical stimulation were similar to the preceding section and the frequencies were 1 to $30 \mathrm{~Hz}$. All frogs exhibited tachypnea followed by apnea to an extent, as well as slight tachycardia and prominent high blood pressure for 20 to $140 \mathrm{sec}$ after stimulation (Fig. 10).

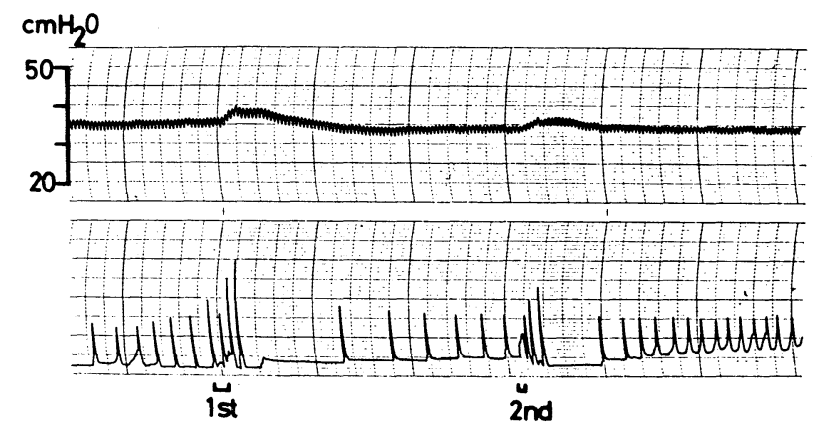

Fig. 10. Effects of trigeminal nerve stimulation on blood pressure and respiration. On response to stimulation, blood pressure was increased and ventilation also increased progressively at first and was followed by apnea.

The latency for induction of such responses was shortened with increasing stimulus frequencies. Most tachypneic patterns transiently observed were of breathing with progressively increasing buccal pressure, and were similar to those seen during hypoxic stimulation (in toads: BoutILIER and ToEws, 1977; in bullfrogs: in preliminary experiments), or in hypercapnia (MACINTYRE and ToEws, 1976).

\section{DISCUSSION}

From results we obtained, it seems that the nasal mucosa mediated the $\mathrm{CO}_{2}$ 
inhibitory reflex in respiration.

SMYTH (1939) presumed that the epithelium in the larynx or the glottis of the frog might perceive $\mathrm{CO}_{2}$. However, we could not confirm his assumption when either $5.7 \% \mathrm{CO}_{2}$ or $14 \% \mathrm{CO}_{2}$ were introduced into the larynx and the glottis which were separated from the internal nares.

Recently, the chemoreceptors responsible for $\mathrm{CO}_{2}$ in the airways or the lungs were demonstrated in mammals and birds (BARTOLI et al., 1974; BousHEY and Richardson, 1973; Fedde and Peterson, 1970; Burger et al., 1976; Osborne et al., 1977). However, in contrast to the $\mathrm{CO}_{2}$ sensor in the nasal cavities of frogs in the present experiments, their $\mathrm{CO}_{2}$ responses generally introduced tachypnea or a greater amplitude of respiration. On the other hand, in cats (BousHEY and RICHARDSON, 1973), it is reported to elicite slowing in breathing with small and inconsistent changes in tidal volume. Fourteen percent $\mathrm{CO}_{2}$ (Fig. 4) as well as $5.7 \% \mathrm{CO}_{2}$ introduced into the buccal cavity immediately induced a greater amplitude in respiration. Sometimes gases other than $\mathrm{CO}_{2}$ for example, $\mathrm{N}_{2}$ or $\mathrm{O}_{2}$ elicited a similar result. Therefore, at present in frogs, the presence of such a specific $\mathrm{CO}_{2}$ sensor that induces respiratory increment as in other species remains uncertain. In these experiments temperature, pressure of flowing gas, or the degree of humidifying the gases being flown into the cavity apparently did not affect this response.

As is generally accepted, the nasal mucosa is innervated by both the trigeminal and the olfactory nerves, and not by other nerves such as the vagus. Both nerves may be afferent nerves concerned with this reflex; in fact, after denervation of both nerves the reflex was abolished (Fig. 6). In this experiment they were stimulated electrically at their proximal end, resulting in depression of respiration or apnea. These results meet the presumption that the afferent nerves from the nasal $\mathrm{CO}_{2}$ sensor are conveyed by these cranial nerves.

It is apparent that the nature of the cardiopulmonary responses induced by $\mathrm{CO}_{2}$ loading to the whole body was similar to the effect of electric stimulation of the olfactory nerves but not that of electric stimulation of the trigeminal nerves (SAKAKIBARA and AKIYAmA, 1977). When applying electric stimulation of the trigeminal nerves, apnea was preceded by a transient 'filling'-like respiration. This response was clearly distinguished from that of the olfactory nerves. One may have to distinguish carefully the role of the trigeminal nerves from that of the olfactory nerves for the nasal mucosa-mediated inhibitory reflex.

It may also be worth referring to the results shown in Fig. 2, where only stopping air flow into the nose mask was shown to induce respiratory inhibition within $10 \mathrm{sec}$. Such observations were repeatedly confirmed in many frogs, and the possibility that gases other than $\mathrm{CO}_{2}$, i.e., $\mathrm{N}_{2}$ or $\mathrm{O}_{2}$ are involved may be excluded because only endogenous $\mathrm{CO}_{2}$ should have accumulated in this situation. Owing to the long latency for the onset of respiratory inhibition, mechanical conditions, such as changing flow rate, also may be excluded from the factors responsible 
for this observation. The above results suggest that the nasal $\mathrm{CO}_{2}$ sensor serves to inhibit pulmonary ventilation in response to $\mathrm{CO}_{2}$ in the range of all expired $\mathrm{CO}_{2}$. In fact, $1.2 \% \mathrm{CO}_{2}$ given via the nose mask, as well as $0.5 \% \mathrm{CO}_{2}$ introduced over the surface of the whole animal were found sufficiently to inhibit respiration (in preliminary experiments). However, it is not known how it affects the ventilation by way of the nasal $\mathrm{CO}_{2}$ sensor in the normal acid-base state or in its extremities.

The latency for respiratory inhibition caused by applying $5.7 \% \mathrm{CO}_{2}$ to the buccal cavities, introduced either externally or internally, was as long as 4-8 sec. Such latencies were intended to become prolonged with decreasing $\mathrm{CO}_{2}$ concentration applied. Since 4-8 sec is longer than the duration of the normal respiratory cycle, breath by breath inhibition by the expired $\mathrm{CO}_{2}$ is supposed tenuous to be accomplished.

When $\mathrm{CO}_{2}$ was given to the frog in a respiratory chamber while its nose was separately being supplied with air through the nose mask, respiration decreased, but its extent was less than that when the whole body including the nasal region was exposed to $\mathrm{CO}_{2}$. More conclusive evidence for the existence of $\mathrm{CO}_{2}$ perception in the skin is shown in Fig. 7 which shows that a frog without an airway $\mathrm{CO}_{2}$ sensor by surgical procedures still depressed its respiration in response to $\mathrm{CO}_{2}$ in the respiratory chamber. This observation agrees with the results of experiment using toads (KATO, 1951).

I wish to thank Dr. Yoshiyuki Honda for his advice and criticism of the manuscript.

\section{REFERENCES}

Bartoli, A., Cross, B. A., Guz, A., Jain, S. K., Noble, M. I. M., and Trenchard, D. W. (1974) The effect of carbon dioxide in the airways and alveoli on ventilation: Vagal reflex studies in the dog. J. Physiol. (Lond.), 240: 91-109.

Boushey, H. A. and Richardson, P. S. (1973) The reflex effects of intralaryngeal carbon dioxide on the pattern of breathing. J. Physiol. (Lond.), 228: 181-191.

BoutilieR, R. G. and Toews, D. P. (1977) The effect of progressive hypoxia on respiration in the toad Bufo marinus. J. Exp. Biol., 68: 99-108.

Burger, R. E., Nye, P. C. G., Powell, F. L., Ehlers, C., Barker, M., and Fedde, M. R. (1976) Response to $\mathrm{CO}_{2}$ of intrapulmonary chemoreceptors in the Emu. Respir. Physiol., 28: 315-324.

Fedde, M. R. and Peterson, D. F. (1970) Intrapulmonary receptor response to changes in airway-gas composition in Galus domesticus. J. Physiol. (Lond.), 209: 609-625.

JONES, D. R. (1970) Experiments on amphibian respiratory and circulatory systems. Exp. Physiol. Biochem., 3: 233-293.

Kato, H. (1951) Studies on normal respiration of frog. Part I. Normal atmung and $\mathrm{CO}_{2}$ effect on it. J. Physiol. Soc. Japan, 13: 319-322 (in Japanese).

MaCINTYRE, D. H. and Toews, D. P. (1976) The mechanics of lung ventilation and the effects of hypercapnia on respiration in Bufo marinus. Can. J. Zool., 54: 1364-1374.

Osborne, J. L., Mitchell, G. S., and Powell, F. (1977) Ventilatory responses to $\mathrm{CO}_{2}$ in the chicken: Intrapulmonary and systemic chemoreceptors. Respir. Physiol., 30: 369-382. 
PRICE, W. M. and BATSEL, H. L. (1970) Respiratory neurons participating in sneeze and in response to resistance to expiration. Exp. Neurol., 29: 554-570.

SAKakibara, Y. and AkIYAma, S. (1977) The $\mathrm{CO}_{2}$ inhibitory responses in respiration of bullfrogs. J. Physiol. Soc. Japan, 39: 252 (in Japanese).

Smyth, D. H. (1939) The central and reflex control of respiration in the frog. J. Physiol. (Lond.), 95: 305-327. 